This item was submitted to Loughborough's Research Repository by the author.

Items in Figshare are protected by copyright, with all rights reserved, unless otherwise indicated.

\title{
Debate: seven ways to be a realist about language
}

PLEASE CITE THE PUBLISHED VERSION

http://dx.doi.org/10.1111/jtsb.12040

\section{PUBLISHER}

(C) 2013 John Wiley \& Sons Ltd

\section{VERSION}

AM (Accepted Manuscript)

\section{PUBLISHER STATEMENT}

This work is made available according to the conditions of the Creative Commons Attribution-NonCommercialNoDerivatives 4.0 International (CC BY-NC-ND 4.0) licence. Full details of this licence are available at: https://creativecommons.org/licenses/by-nc-nd/4.0/

\section{LICENCE}

CC BY-NC-ND 4.0

\section{REPOSITORY RECORD}

Elder-Vass, Dave. 2019. "Debate: Seven Ways to Be a Realist About Language". figshare. https://hdl.handle.net/2134/17420. 


\section{Seven ways to be a realist about language}

\section{Dave Elder-Vass}

$\underline{\text { d.elder-vass@1boro.ac.uk }}$

Note: This is a pre-publication version of a paper published in the Journal for the Theory of Social Behaviour. It may differ slightly from the published version. Please cite as: Elder-Vass, D. (2014) 'Seven ways to be a realist about language', Journal for the Theory of Social Behaviour, 44:3, 249-267, and refer to the published version for the final wording and pagination.

\footnotetext{
Abstract

There are many differing ways to be a realist about language. This paper seeks to classify some of these and to examine the implications of each for the study of language. The principle of classification it adopts is that we may distinguish between realisms on the basis of what exactly it is that they take to be real. Examining in turn realisms that ascribe reality to the external world in general, to causal mechanisms, to innate capacities, to linguistic signs, to social structures, to language systems, and to linguistic groups, the paper summarises the case for a particular critical realist ontology of language. In the process, it engages briefly with the work of Saussure, Chomsky, Halliday, and more recent explicitly realist thinkers such as Bhaskar, Pateman, Archer, Sealey and Carter. One implication is that language itself is not a phenomenon that separates us from a causally structured world, but rather a part of that world, a part with an identifiable causal structure of its own that is similar to that of other normative phenomena.
} 


\section{Seven ways to be a realist about language ${ }^{1}$}

The study of language occupies an ambivalent place in the scholarly disciplines, situated as it is at an intersection between the humanities, the social sciences, and the natural sciences. One consequence is that it has been a battleground for schools of thought emanating from all of these, and it is one group of these battles that forms the background to this paper: conflicts between realist and anti-realist accounts of language and the world. Many scholars of language have been influenced by anti-realist arguments that once circulated widely in the humanities and the social sciences. Indeed, the anti-realist tendency was at one time known as "the linguistic turn". By contrast, anti-realist views are typically rejected - or simply ignored - by those who consider themselves scientists of language. Increasingly, they are also being explicitly rejected by philosophers of language and by linguists from other traditions, and it may be that many more linguists implicitly adopt realist assumptions. It has even been suggested that "the 'spontaneous' practice of much linguistics is consonant with realism, despite the fact that in their metascientific reflections many linguists take an anti-realist stance" (Pateman, 1987: 18),

This paper examines what it could mean to be a realist about language. But there are many ways to be a realist about language. The paper classifies some of these, and briefly examines the implications of each for the study of language. The principle of classification it adopts is that we may distinguish between realisms on the basis of what exactly it is that they take to be real. It examines in turn realisms that ascribe reality to the world in general, to causal mechanisms, to innate capacities, to linguistic signs, to social structures, to language systems, and to linguistic groups. In the process, it engages with the work of a number of scholars who have adopted realist approaches to language. These various ways of being realist are not necessarily consistent with each other, but nor are they necessarily incompatible. Most varieties of linguistic realism are defined, not by allegiance to one of these ways of being a

\footnotetext{
${ }^{1}$ This paper arises partly from discussions at the symposium on Realism and Language organised by Alison Sealey and Bob Carter at Warwick University in January 2011. I would like to thank all the participants for their stimulating and challenging contributions. Of my many other debts, perhaps the most significant is to Peter Patrick, for his advice on sociolinguistics and speech communities. 
realist, or all of them, but by the adoption of a certain set of them (and there are therefore many more than seven permutations of these alternatives). Indeed, at least some varieties of linguistic realism are also compatible with some of the arguments that the anti-realist tradition has regarded as its own (notably moderate versions of social constructionism).

This analysis is not a comprehensive survey of all possible ways to be a realist about language, or even of all the actual varieties of realism about language; but only a selection of particular varieties that provides an orienting framework. As such it is necessarily brief and somewhat superficial in its comments on the various traditions it touches upon. But the paper is not only a descriptive account of realisms; it also offers at least the overview of a case for some varieties of linguistic realism, and against others. Ultimately it endorses a variety of critical realism, but as will become clear, mine is still only one of the ways in which it would be possible to be a critical realist about language.

\section{First way: empirical realism}

The most basic realism of all is the belief that the world in which we exist as individuals exists (and extends beyond us) independently of what we think about it. ${ }^{2}$ Of course, the locution 'we' already assumes something of the sort, so a more rigorous version of the claim, a version that could coherently be denied, is that the world in which $I$ exist, exists (and extends beyond me) independently of what I think about it. To deny such a claim would make one a solipsist: someone who believes that there is nothing beyond their own thoughts and feelings, and that everything else they might otherwise take to be real is merely a figment of their imagination. While it is impossible to prove absolutely that solipsism is wrong, it seems wildly implausible, and each of us conducts our life on the assumption that it is false. For our first group of realists it is so overwhelmingly likely that the world 'out there' exists that we can take this as a firm working assumption.

\footnotetext{
${ }^{2}$ I avoid the term 'external world', in order to avoid any dualistic implication that the world beyond us is ontologically separate from us; we are very much part of the world that extends beyond us.

D. Elder-Vass 
We may call this empirical realism, as it implies that the phenomena we experience are real. ${ }^{3}$ Despite its simplicity, this is already a position that separates us from the most extreme rhetorics of anti-realist constructionism. As Burr puts it, "Social constructionism is not claiming that language and discourse merely have a strong influence upon our perception of reality. What we know as reality is itself a social construction" (Burr, 2003: 80). One of the more forthright exponents of this view is Kenneth Gergen:

we must suppose that everything we have learned about our world and ourselves that gravity holds us to the earth, people cannot fly like birds... - could be otherwise... we could use our language to construct alternative worlds in which there is no gravity or cancer, or in which persons and birds are equivalent (Gergen, 1999: 47).

Gergen is not saying that our language creates the material world, but he is saying that the only kind of reality we have access to is a linguistically constructed sense of reality, ${ }^{4}$ and therefore that all the experiences and understandings of it that we can have can be changed by changing our language. This position is not strictly speaking anti-realist in the sense of denying that there is a world that extends beyond us, but it is a-realist, since such authors take the view that there is nothing we can say about whether there really is an external world (Collier, 1998: 47). ${ }^{5}$ Ironically, many radical constructionists, while insisting on a-realism in principle, are quite happy to accept the reality of the everyday world with which they interact in practice - as if it were perfectly reasonable to deny in our philosophy that which we rely on in our actual lives. Edwards, Ashmore, and Potter, for example, argue that we can retain "a common-sense notion of reality" while nevertheless "letting go of realism" (Edwards et al., 1995: 36).

Empirical realism is also already a position that is relevant to the study of language itself. Language is instantiated in communications between people, and it is

\footnotetext{
${ }^{3}$ Note that the labels I give these forms of realism are not meant to be applicable beyond the scope of this paper, and may not correspond to usages elsewhere. For example, Bhaskar uses empirical realism to refer to a position that not only recognises that the empirical is real but also denies that deeper causal forces are (Bhaskar, 1975: 15-16).

${ }^{4}$ Amongst linguists, Halliday seems to imply a similar view when he says that "reality consists of meanings" (Halliday, 1978: 139).
} 
hard to see how we could take the study of language seriously without accepting at least that those people are real, existing independently of other people's thoughts about them, and that there are real events in which those people make use of language and the physical media through which it is transmitted to communicate. Indeed, the study of language would be impossible if participants and linguistic observers did not have access to linguistic communications that are part of the world beyond us. Linguistic constructionists like Gergen assume that we have access to linguistic communications, but not to the world beyond us: but these views cannot both be sustained simultaneously. If we had no access to the world beyond us we would have no access to communications either. Linguistic communications depend on events that occur independently of what people other than those speaking or writing might think about them (Elder-Vass, 2012: chapter 12).

Perhaps the minimal requirement of a realist understanding of language, then, is that it be consistent with empirical realism. As Devitt and Sterelny have said: "It is, of course, conceivable that realism is false. But its epistemic security is vastly greater than any doctrine in philosophy of language or philosophy of mind" (Devitt and Sterelny, 1999: ix-x). Or indeed any doctrine in radical linguistic constructionism.

\section{Second way: scientific realism}

Realism becomes more ambitious when it addresses itself not just to the existence of external reality but to the question of causality. For scientific realists, events are not just a random jumble of occurrences but are caused, and caused by potentially identifiable factors. Furthermore - and this is what differentiates scientific realism from positivist analyses of cause in the covering law tradition of Hume and Hempel - causality is something more than an observable regularity in the flow of events, a pattern in which an A event is consistently followed by a B event. For scientific realists, to say that ' $\mathrm{B}$ always (or usually) follows $\mathrm{A}$ ' is not to offer a causal explanation of $\mathrm{B}$, but to describe a phenomenon that needs to be explained. One might therefore question, for example, the statement that "frequency patterns as revealed in

\footnotetext{
${ }^{5}$ This is a case of what Bhaskar has called the epistemic fallacy, the error of believing "that statements about being can be reduced to or analysed in terms of statements about knowledge" (Bhaskar, 1975: 36). 
corpus studies provide explanations for historical change" (Halliday, 1991: 33): for a scientific realist, frequency patterns are phenomena that need to be explained, not explanations. More charitably, we can see frequency patterns as evidence that might help us identify the mechanisms that produce them. The analysis of a linguistic corpus for frequency patterns, for example "identifies trends and probabilities", providing evidence that may help to identify the constraints that influence our communications (Sealey, 2009: 226), but frequency patterns as such are not explanations of anything.

Scientific realism itself comes in many varieties; this paper will employ the version developed in the early work of Roy Bhaskar (Bhaskar, 1975). Bhaskar examines the logic behind scientific experiments, in which scientists try to exclude as many causal factors as possible from influencing a particular event in order to focus on the causal significance of just one factor. Such activities presume one of the key features of Bhaskar's account of causation, a feature that already distinguishes it from the covering law theory: multiple determination, the view that events are caused by the interaction of many different causal factors. If this were not the case there would be no point in scientists designing experiments in ways that seek to exclude some of these factors. This, however, is not the central point of Bhaskar's argument. In designing experiments this way, scientists seek to create closed systems: sets of circumstances in which only a limited set of causal factors are significant, so that they can study the effects of one causal factor at a time. But this would be pointless if these causal factors did not also operate outside the laboratory, in open systems, where their effects are mixed with those of other causal factors (Bhaskar, 1975: 33-4), otherwise what they learn in the laboratory would be useless outside it. The whole logic of scientific experiments, in other words, assumes (very successfully) that events are caused by multiple interacting causal factors, each having a tendency to produce certain sorts of effects, but that such tendencies may be frustrated by the interference of other factors.

Bhaskar goes on to argue, in line with other scientific realists, that these tendencies are causal powers of things, and that these powers are emergent properties of the things concerned, which are produced by generative mechanisms. ${ }^{6}$ These generative mechanisms are themselves the outcome of processes of interaction between the parts of the thing (or entity) concerned (Elder-Vass, 2010a: chapters 2

\footnotetext{
${ }^{6}$ For other causal powers theories, see for example (Bunge, 2003) and (Groff, 2008).

D. Elder-Vass
} 
and 3). Thus there are deeper forces that may sometimes be unobservable operating to produce the events that we do observe. This implies that explanatory work requires two complementary types of investigative activity. On the one hand we need to examine what mix of causal powers contributes to causing a particular event (or class of events), an activity we may call retrodiction (Lawson, 1997: 221). On the other, we need to explain each of these causal powers by examining the mechanisms that produce them, an activity called retroduction (Lawson, 1997: 24).

Scientific realists, then, are distinguished by the belief that not only the phenomena that we experience empirically but also the potentially unobservable causal powers and mechanisms that lie behind those events are real. As far as language is concerned, the phenomena we experience are communicative acts Searle's speech acts, or instances of Saussure's parole. But what are the causal powers that interact to produce these events, and the mechanisms that produce them? One part of the answer is surely that people have causal powers that contribute to the production of communicative events, and one part of linguistic explanation must be concerned with the mechanisms behind the powers that people have to communicate. But the model of multiple determination encourages us to think that other entities with other powers may also contribute (Sealey and Carter, 2004: 12). As numerous linguists have argued, for example, the production and understanding of communicative acts is influenced not only by the speaker but also by various aspects of the speaker's context. Volosinov, for example, tells us that "the situation shapes the utterance" (Volosinov, 1996: 75). Such influences, no doubt, are mediated by the individual's perception of them, but this suggests at the very least that our causal power to perceive our surroundings influences the utterances we make and the interpretations that we make of those of others. More challenging are questions (discussed below) of whether and how wider social influences might exercise a causal influence on our communicative acts.

Another implication of scientific realism is that we need to sustain a clear distinction between, on the one hand, actual events, and on the other, the causal structures that produce them. This calls into question statements like "It is... unnecessary to make a sharp distinction between abstract and actual language structure - the sort of distinction embodied in Saussure's langue and parole or Chomsky's competence and performance" (Sinclair, 1991: 103). Similar arguments 
have been advanced by Halliday (Halliday, 1991) and by integrationist linguists (see Sealey and Carter, 2004: 22). Such statements seem to represent a denial of scientific realism from an empiricist standpoint; a rejection of the argument (implicit, for example, in both Saussure and Chomsky: Pateman, 1987: 20) that there are persistent mechanisms that lie behind the production of communications. The best kind of response to such arguments is to make progress in the identification of these mechanisms.

\section{Third way: Nativist realism}

Perhaps the best known attempt to identify the mechanisms underlying human linguistic capacities is the work of Noam Chomsky. Although the specifics of his argument have developed over the years, the common theme is that he regards human linguistic competence as a product of biologically innate capacities. To take one version, he argues that humans are born with a "language acquisition device", a language-specific module of the brain that already contains knowledge of specific principles of grammar, which the developing child connects up to her experience of the particular language(s) she is exposed to in order to develop her linguistic competence (Chomsky, 2000: 4).

A number of scholars have argued that this is a realist view, and indeed one that is compatible with both scientific realism in general and critical realism in particular, because it seeks to identify the mechanisms that generate our power to speak in a grammatically competent way. Pateman, in particular, points to

one of Chomsky's frequently deployed arguments for distinguishing the language faculty and linguistic competence from other faculties and competences: just because many faculties and competences interact in the actual production and understanding of speech, which is consequently the joint product of an (open) set of complicated mechanisms, that does not mean that as scientists we should not have as a primary goal the isolation and description of the powers and liabilities of individual mechanisms (Pateman, 1987: 8).

Chomsky, it seems to Pateman, is pursuing the scientific realist approach to retroduction introduced above. The idea that linguistic competence is at least partly the product of an internal structure is very consistent with the realist account of mechanisms, and Chomsky, according to Pateman, recognises that such competence is merely one of the factors that "interact in the actual production and understanding of 
speech". Chomsky has also said, for example, that his theoretical concepts "refer to something real - typically, some state or property of the brain" (Chomsky, 1993: 28). This is at the very least a commitment to empirical realism, but since brain states are largely inaccessible to us, it also seems to be a scientific realist commitment to examining underlying mechanisms (also see Chomsky, 2000: 134).

As is typical of substantive scientific theories, Chomsky's entails not only a general commitment to scientific realism, but also a more specific commitment to the claim that some specific entities, powers or mechanisms are real and thus causally significant. We may designate as nativist realism this view that the innate human language acquisition device is real. It should be clear scientific realism does not entail a committment to every substantive theory that is consistent with scientific realism. Indeed, there may be multiple competing theories of the same phenomena that are equally compatible with scientific realism without being equally scientifically sound. Hence it is entirely open to scientific realists to dispute Chomsky's specific claims, as so many linguists have done, even if they accept that he takes a scientific realist approach.

Peter Jones, however, has gone one step further and questioned whether Chomsky's work is consistent with the critical realist version of scientific realism at all (Jones, 2003). Jones accuses Chomsky of a "dogmatic reductionism" in which, in effect, language is explained purely in terms of biological capabilities. ${ }^{7}$ While Chomsky does offer a mechanism to explain linguistic competence, we might say, he confines his attention purely to one mechanism and treats all others as trivial and unimportant by comparison. Despite his nominal acceptance that social experience is relevant to setting the parameters of any individual's particular linguistic competence, and his nominal acceptance that the point of retroducing linguistic competence is to contribute to explaining actual communicative events by identifying one of the multiple causal factors involved, in practice he treats everything but innate capacities as irrelevant to linguistics. Numerous critics, for example, have accused him of ignoring real speech events (e.g. Beaugrande, 1998; Sealey and Carter, 2004: 61) and sociocultural influences on them (e.g. Hymes, 1972). In general, Jones, argues, such reductionism "results in the disappearance (or extreme marginalisation) of social,

\footnotetext{
${ }^{7}$ Jones also offers other grounds for questioning Chomsky's realism, which I do not have the space to consider here.

D. Elder-Vass
} 
cultural and historical processes as explanatory factors in human affairs" (Jones, 2003: 95-6).

The neglect of all but one causal factor in the production of linguistic acts leaves Chomsky with a rather stunted form of scientific realism and the neglect of all but the innate even in the production of linguistic competence seems to leave Chomsky's theory vulnerable on scientific and not just metaphysical grounds. While there is good evidence that some parts of our linguistic ability depend upon innate and largely language-specific features of the brain (e.g. Pettito, 2005), even our linguistic competence (let alone our linguistic performance) also depends on other factors for its development. The development of our linguistic capacities seems to be a process "in which biology contributes some portion of the answer, and experience another... in a complex synergy" (Elman, 1999: 2). Once again, Chomsky's account seems to focus on one kind of causal factor to the exclusion of others that are equally relevant.

A more rounded linguistic realism, then, will need to recognise the contribution of other kinds of causal factors to the production of language and linguistic capabilities in individuals. The realist framework of multiple determination, however, means that this need not be at the expense of recognising the contribution of biological factors too (Pateman, 1987: 81; Searle, 2002).

\section{Fourth way: semiotic realism}

For another part of the picture, we may turn to the work of Ferdinand de Saussure. ${ }^{8}$ While Saussure's semiology, or semiotics, is often associated with antirealist or a-realist thinking due to its adoption by poststructuralism, it has no necessary connection to such views. This section will argue that much of Saussure's work (and perhaps all, depending on how it is read) is thoroughly compatible with a realist account of language.

Perhaps the best known element of Saussure's work is his account of signification, in which he analyses the linguistic sign into the signifier and the signified: a sound-pattern (or rather a range of sound patterns) and a concept (or rather a range of concepts) with which it is associated by the sign. The linguistic sign, for

\footnotetext{
${ }^{8}$ The issues covered in this section are discussed in much greater detail in (Elder-Vass, 2012: chapter $5)$.

D. Elder-Vass 
Saussure, is a mental property of a human individual, and in analysing it he is examining one of the mechanisms that enable an individual to produce and to interpret speech. ${ }^{9}$ The individual who knows what conceptual content she wishes to express can (subconsciously) transform this into a sound pattern that can be used to express it by means of accessing the corresponding mental sign(s), and the process operates in the opposite direction to provide us with a mechanism for interpreting spoken language, or at least some part of its content. For Saussure, like Chomsky, his central theoretical concept refers to something real, a property of the mind or brain. And it refers to something that is of interest because of the role it plays when we produce and interpret linguistic events. We may designate this view that signs are real and causally significant as semiotic realism.

Saussure's theory of signification has often been invoked by anti- or a-realist thinkers. Many of these have assumed that Saussure's well known emphasis on the arbitrariness of signification destabilises the understanding of the relation between language and the world that is characteristic of realism: the notion of reference. As Gergen puts it,

if language use is determined by an inner logic, then what we call 'meaning' may be independent of the world outside language. Or to put it in another way, words and phrases may gain their meaning from their relationship to other words and phrases, and without regard to 'the way the world really is' (Gergen, 1999: 26).

If the relation of language to the world is arbitrary, in other words, then the structure of language may determine the way we think and talk about the world, rather than the way we think and talk about the world being influenced primarily by our experience of the world itself. Such views cannot possibly be justified by Saussure's account of arbitrariness, which merely states that in any given language, some other sound pattern (than the one that is actually embedded in the sign concerned) could equally well have been selected to correspond to any given concept. Saussure's arbitrariness lies in the relation between signifier and signified, not in the relation between the concept signified and the world (Elder-Vass, 2012: 92-98).

\footnotetext{
${ }^{9}$ One reason why this is only one of the mechanisms is that language is composed of more than signs; Saussure's analysis is not directed, for example, at the grammatical understandings we also need in order to produce or interpret linguistic events. Despite this, recent suggestions that lexis and grammar blend into one another (see Sinclair, 1991: e.g. 6, 108) perhaps imply that Saussure's signs might have some relevance to grammatical knowledge. 
Anti-realist readings of Saussure have also been inspired by his statement that "in a language there are only differences, and no positive terms" (Saussure, 1986 [1916]: 118). The meaning of Saussure's statement is unclear, and its ambiguity is increased by the discussion that follows it, including, for example "Although signification [signified] and signal [signifier] are each, in isolation, purely differential and negative, their combination is a fact of a positive nature" (Saussure, 1986 [1916]: 118-9). The original statement appears to refer to Saussure's notion of value, which we can interpret as the range of concepts included in a signified, and also the range of sound-patterns included in a signifier. Such ranges, he seems to be saying, are defined by what is excluded from them. But this does not prevent successful reference. ${ }^{10}$ Reference to specific features of the world is not achieved within the sign, but when the sign is put to use in parole, and the broadness of the range of concepts, for example, to which a word might refer in the sign at rest is resolved into specific reference when it is employed in a linguistic act (see below).

Ironically, realists have sometimes committed a similar error in criticising Saussure's theory of signification. ${ }^{11}$ Since the work of Ogden and Richards (Ogden and Richards, 1923), Saussure has been accused of failing to take account of the relation of the sign to the external world (e.g. Smith, 2010: 161-2). In their "triangle of signification", Ogden and Richards added a third element to the signifier and the signified, to create a "trilateral model" of the sign. This third element is the referent, the object in the external world to which the sign refers (Harris, 2003: 69-70; Joseph, 2004: 75). Some realists have repeated this argument, suggesting that Saussure's semiology is incompatible with critical realism, on the grounds that "the Saussurean sign (the signifier/signified pair) involves nothing akin to a referent or object, and if it doesn't exclude the extra-mental world altogether, certainly gives it no role within the signification process" (Nellhaus, 1998: 2). Roy Bhaskar has also written of the need to see semiosis in terms of a triangle that includes the referent (Bhaskar, 1993: 222-3), but, crucially, stops short of saying that the sign itself has three parts.

\footnotetext{
${ }^{10}$ As Collier puts it, "people think that Saussure has shown that words get their meaning from their relation to other words, not by referring to reality. But what he has in fact shown is that words refer to reality by virtue of their relation to other words" (Collier, 1998: 48).

${ }^{11}$ The following three paragraphs draw heavily on chapter 5 of Elder-Vass (2012).

D. Elder-Vass
} 
There is something right in these critiques, but also something wrong. Consider, first, what is wrong. In developing a synchronic account of the sign as a mental phenomenon, Saussure is seeking to isolate the "relevant psychological reality for current speakers of the language" (Harris, 2003: 197). While on occasion speakers may have, as part of their psychological reality, current perceptual awareness of some object to which they are referring, this is distinct from the structure of the sign, and it is by no means a prerequisite to the use of the related sign. A person can speak about a cat, for example, despite the fact that no cat is present when she does so. Furthermore, the sign is a mental phenomenon, as are its parts, but cats and other external referents are not mental properties and so could never be a part of the linguistic sign.

What is right in these critiques, by contrast, is that when we use signs, and when we learn signs, reference to the external world is involved. We cannot make sense of the achievement of meaning in actual speech acts without recognising the role of reference. Once we turn to the use of signs and the learning of signs we step outside the strictly synchronic analysis that Saussure provides in his theory of the structure of signs. For Saussure the process by which meaning is resolved in actual cases belongs to parole, and not in the structure of langue. His synchronic linguistics examines the structure that enables the sign to participate in the process of parole, but not yet how it actually does so - something he might have addressed in the linguistics of parole that he saw as a necessary complement to the linguistics of langue but was unable to deliver before his death (Saussure, 1986 [1916]: 19-20).

Although Saussure like Chomsky therefore neglected linguistic events, this was something of a historical accident. And unlike Chomsky, he did stress that language is thoroughly dependent on social influences. The remainder of this paper considers how such dependence may be theorised from a variety of realist perspectives.

\section{Fifth way: social realism}

The realist tradition in the social sciences is strongly committed to the view that social influences are the product of social structures; while there are many ways of understanding this concept (Elder-Vass, 2010a: 76-86), the core intuition is that when people interact the outcome is social forces that are in some sense more than the sum of the parts. Some earlier theorists of social structure were perhaps sociological 
holists, characterised by the view that social structures determine social events over the heads, as it were, of the people involved in them. But contemporary advocates of the concept, from a variety of traditions, are committed to the view that both social structure and individual human agency are causally significant to the (multiple) determination of social events.

Critical realists, for example, are "committed to an explanatory model in which the interplay between pre-existing structures, having causal powers and properties, and people, possessing distinctive causal powers and properties of their own, results in contingent yet explicable outcomes" (Sealey and Carter, 2004: 12). Social realism, on this account, is the claim that social structures (and cultural structures, if they are different) are real and causally significant, and may be contrasted with methodological individualism, which insists that it is only human individuals that can have a causal impact on social events.

For critical realists, the causal powers of social and/or cultural structures are distinct from those of human individuals, but they are not entirely independent of them. One way of portraying part of the relationship between the two is Margaret Archer's morphogenetic cycle - or the very similar Transformational Model of Social Activity developed by Roy Bhaskar (Bhaskar, 1998 [1979]: 33-37). Archer sees the relationship between structure and individual human action as a cyclical one. In the first phase of the cycle, individuals are influenced by the existing social structures and their knowledge of them; in the second, they act, in ways that are affected by these influences but also by other factors; and in the third, their actions contribute (along with those of many others) to reproducing or transforming (subtly or radically) the pre-existing structures (Archer, 1995: 154-161).

Such a model is easily transposed into a linguistic context, and provides a framework for theorising the relation between individual linguistic actions and the wider context. Although the model is presented as an account of the relationship between individuals and a single social structure, in practice many structures exist in parallel, interact in influencing actions, and may be reproduced and/or transformed as a result of the same actions. Thus, for example, social structures like class systems and organisations can influence linguistic practice at one and the same time as more specifically linguistic structures do so. 
Archer's morphogenetic cycle is highly plausible, but still quite an abstract model of the relation between structure and agency, and if we are to develop a more specific understanding of its significance for language, we will have to become more concrete. In doing so, we will find that there is more than one way of being a social realist about linguistic structures.

\section{Sixth way: linguistic systems realism}

The first of these is the idea that there is a linguistic system that is independent of what exists in the heads of individuals, but that does influence what exists in our heads, and hence is real. Saussure is one of many linguists who have used this term (e.g. Saussure, 1986 [1916]: 118), but it is not immediately apparent what it refers to, and different scholars may have different referents in mind.

Halliday, for example, seems to use the term to refer to the range of possible uses of language and the relative frequency or probability with which each is used: "It had always seemed to me that the linguistic system was inherently probabilistic, and that frequency in text was the instantiation of probability in the grammar" (Halliday, 1991: 31). Describing this perspective, Carter and Sealey say "we could consider each instance of the production of a particular way of saying things as the 'micro' level, produced by individuals. The repetition of these forms over many macro instances would then generate the 'macro' level of system or structure" (Carter and Sealey, 2000: 15). It is difficult to see how a linguistic system, conceived in this way, would provide a structural influence on individual language users. The instances of speech that are its constituents are spread over time, rather than existing at the particular time when they would have some influence, so in order to have some influence they would need to be stored in some persistent form. The obvious form would be as memories (or neurological abstractions from memories) in the minds or brains of individual speech users. But there's nothing inherently structural about such memories, and they would differ from individual to individual. On such an interpretation, the linguistic system would be entirely compatible with methodological individualism.

Is there some other form in which a linguistic system could exist? Many scholars have been tempted by the belief that 'ideas' can exist in systems independently of what exists in any individual's head. Perhaps Halliday has 
something like this in mind when he says that "A social reality (or a 'culture') is itself an edifice of meanings - a semiotic construct. In this perspective, language is one of the semiotic systems that constitute a culture" (Halliday, 1978: 2). Though Halliday is far from explicit about the form that such systems take, at least some of those who express this kind of view seem to believe that systems of meanings or ideas can exist in some abstracted form that can float freely of individual human belief. They are, in other words, idealists. For a realist, this is intensely problematic. If ideas can exist in some form outside of individual heads, then we need to know more about this form, and we need to know how ideas in such a form could influence us.

Some realists, most prominently Margaret Archer, have offered an answer to this question which seeks to avoid idealism, which we may designate cultural realism or cultural systems realism. ${ }^{12}$ Archer's account of cultural systems is based on Karl Popper's concept of "World 3 knowledge". Popper's World 1 is the ordinary physical world, and World 2 is the knowledge, beliefs, and dispositions of human individuals. By contrast, World 3 is "the world of objective contents of thought, especially of scientific and poetic thoughts and of works of art" (Popper, 1979: 106). This World 3, according to Popper, contains "knowledge without a knowing subject" (Popper, 1979: 109), "knowledge in the objective sense, which consists of the logical content of our theories, conjectures, guesses" (Popper, 1979: 73). So far, this seems no different from idealism, but what distinguishes Popper's position is that the contents of World 3 are those ideas that are encoded in material artefacts - in books, newspapers, documents, films, and so on. World 3 , in other words, is embedded in a physical archive that has a material existence independently of the thoughts of individual human beings and thus can influence them causally.

Archer adopts Popper's argument and applies it, not to knowledge, but to culture. "At any time," she argues, " a Cultural System is constituted by the corpus of existing intelligibilia - by all things capable of being grasped, deciphered, understood or known by someone" (Archer, 1996 [1988]: 104). These 'intelligibilia' are those World 1 material artefacts from which we can extract cultural meaning. But the

\footnotetext{
${ }^{12}$ I have discussed Archer's position at length in (Elder-Vass, 2010b) and (Elder-Vass, 2012: chapter 3), and debated it with her in (Archer and Elder-Vass, 2012). The following material draws on these sources.
} 
Cultural System itself consists of the ideas that are expressed in them rather than the material objects themselves.

Alison Sealey and Bob Carter have sought to apply this kind of thinking to the linguistic system. Citing Popper, they suggest that "World 3 is the realm of the externalized products of the engagement of the human consciousness with the world beyond itself" (Sealey and Carter, 2004: 37) (also see Carter and Sealey, 2000: 11 12). They connect this to language via Archer's concept of cultural emergent properties: "we will argue for a view of language as a cultural (not a material) emergent property, not detachable from human beings but emergent from their biological attributes and their practical engagement with the world" (Sealey and Carter, 2004: 32). Hence, "As a cultural resource and a 'World 3' entity... one of the properties which language possesses... is an objective existence" (Sealey and Carter, 2004: 119).

Cultural realism, however, and thus this variety of linguistic systems realism, is built on rather questionable foundations. It is easy enough to accept that books and other linguistically coded material artefacts are real things capable of causal influence, but these arguments depend on quite a different claim: that the 'ideational content' of such artefacts is real, independently of what we may think about it. But I question whether these objects contain knowledge or culture as such: marks on paper, for example, have no informational content in the absence of a reader. Within books, then, there is no knowledge or culture, only marks that may be used to communicate them; and when that communication is completed successfully, what is produced is subjective (World 2) and not objective (World 3) knowledge or culture.

As David Bloor puts it, “The central worry for any reader of Popper's book is: What exactly is the third world? What mode of being does it have?" (Bloor, 1974: 75). Knowledge or ideas can exist as mental properties, but outside the brain, I argue, there is no way for ideas as such to exist. If this is so, the ideational content of neither knowledge nor culture can exist as a system outside the brain, and there can be no such thing as a linguistic system that takes a World 3 form.

There is perhaps some similarity between my argument here and some aspects of Chomsky's critique of E-languages (Collins, 2008: chapter 6). In criticising the concept of E-languages, Chomsky seems to be attacking several different targets at once, not all of them very explicitly, including (a) the significance of actual speech 
and other communicative events for linguistics; (b) the idea that a language is a set of sentences rather than a set of rules or competences (Collins, 2008: 140); (c) the possibility that there is something social, something outside the individual, that is causally significant to linguistics; (d) the coherence of the idea that there are welldefined languages, such as English or German (Hornstein, 2005: 158); and (e) the idea of language (or of $a$ language) as an abstract ideal system external to the human mind. I would not endorse all of these criticisms, but the last of them maps closely onto the argument presented here.

One implication of this argument is that the sense we sometimes have of an objective external language system is an illusion. But I do want to argue, nevertheless, that social realism can be applied to language. If this is so, then we will need to be realists about some other type of linguistic social structure.

\section{Seventh way: linguistic norm circle realism}

That other type of linguistic social structure is what I have called linguistic norm circles, or linguistic circles for short. These concepts are explained in detail elsewhere: the concept of norm circles in Elder-Vass (2010a: chapter six) and ElderVass (2012: chapter two), and their application to language in Elder-Vass (2012: chapter six). Here I can only briefly sketch the argument, ignoring many of the complexities that are discussed there.

A norm circle is the group of people who are committed to supporting a particular norm, by endorsing and enforcing it in their relations with others. All normative social institutions, I have suggested, are the causal products of norm circles, which have the causal power to increase the tendency of human individuals to comply with the norms that they support. The mechanism by which they do this is as follows: the members of the norm circle endorse and enforce the norm, for example by praising or rewarding those who comply with it and by criticising or punishing those who do not. Those who experience such norm-supporting behaviour, whether it is directed at them or not, come to understand that they live in a normative environment in which they are expected to comply with the norm concerned. This increases their tendency to observe the norm, whether for purely instrumental reasons - they wish to avoid criticism or punishment, for example - or because they come to 
internalise the norm as a kind of moral standard to which they feel a personal commitment. In either case, they may also go on to start endorsing and enforcing the norm themselves.

Although I do not suggest that norm circles are the only kind of social structure, I do argue that they are a particularly important kind, because they underpin a whole variety of social phenomena. Organisations, for example, although they are a kind of social structure in their own right, depend on the norms embedded in role definitions for their structure. Culture, likewise, is essentially normative, and I have argued that discourse and knowledge can also be explained at least partly in terms of the influence of certain kinds of norm circles (Elder-Vass, 2011; Elder-Vass, 2012: chapters three, eight, and eleven). For the purposes of this paper, however, norms are significant because language itself is essentially normative. Wolfram, for example, tells us that "all language communities engage in language norming, that is, the establishment of appropriate models of language behaviour" (Wolfram, 2003: 251). This section argues that, to the extent that linguistic practices are standardised, this is the result of the causal impact of norm circles on linguistic behaviour. We may call norm circles that produce linguistic norms linguistic circles, but linguistic circles are merely a type of norm circle. They work in just the same way as other norm circles, but relate to only a subset of norms: those that regulate the various aspects of linguistic practice, including for example those that regulate what words are taken to mean (hence linguistic signs are norms), how we may combine them to form grammatical sentences, and how we should pronounce them. ${ }^{13}$

The linguistic circle has something in common with the sociolinguistic concept of a speech community, but also some significant differences from the ways in which this concept is commonly used. Perhaps the most striking difference is that linguistic circles are deliberately defined in terms of a single linguistic norm, whereas speech communities are usually defined in more complex terms (Hudson, 1980: 29). When this is so, the speech community model builds in assumptions about the relations between social similarities on different dimensions, whereas each linguistic circle relates to one and only one linguistic norm, and any relations that may exist between the linguistic circle and other social groupings or similarities are contingent and open to empirical investigation.

\footnotetext{
${ }^{13}$ And indeed intermediate types, such as lexico-grammatical norms (Sinclair, 1991).

D. Elder-Vass
} 
It is not only the relations between linguistic circles and non-linguistic groupings that are contingent and open: linguistic circles themselves are diversely intersectional. The group of people that endorses and enforces any given linguistic norm need not have the same membership as the group that endorses any other, irrespective of whether the norms they represent are commonly considered parts of the same language, register, or other linguistic subdivision. As Hymes puts it, "if one analyses the language of a community as if it should be homogeneous, its diversity trips one up around the edges. If one starts with analysis of the diversity, one can isolate the homogeneity that is truly there" (Hymes, 1972: 276) (cf. Halliday, 2007: 205). In recognising linguistic circles as the causal forces behind the standardisation of individual linguistic practices, then, we need not commit ourselves to the notion of a language as a unified and well-demarcated system.

This is not to deny that languages can sometimes approximate to this sort of model. They may do so, for example, when a group is very isolated from other linguistic groups, or when there are powerful political forces driving convergence, for example states that use their educational systems to support the standardisation of a national language. One implication of this is that linguists themselves, as providers of prescriptive statements about a language in, for example, grammar books and dictionaries, may play a significant part in linguistic norm circles (Wolfram, 2003: 253). Such artefacts become a transmission mechanism for normative influence, with their authors being members of the norm circles concerned.

Although the linguistic circles model is a model of the influence of social structure on linguistic practice, the power to choose how to speak remains with the individual. Those choices, however, are shaped by dispositions, which are themselves the product of the individual's causal history of interaction with the world (ElderVass, 2010a: chapter 5). Our specifically linguistic dispositions are produced by our interactions with the members of linguistic circles, and we may often implement them unthinkingly, thus reproducing our linguistic environment. But when there is conflict between different linguistic norms, as there may often be in the complex contemporary social world, or ambiguity in how the norms apply to a situation, it is the individual that must resolve this conflict into determinate patterns of speech, whether consciously or not. Such conflicts and ambiguities also create the 
opportunity, and sometimes the need, for individuals to indulge in incremental creativity in their use of the language.

\section{Conclusion}

This paper has examined critically some different ways in which we could be realists about language, largely by considering what kinds of powers and mechanisms might be causally significant to its production and interpretation. It is far from comprehensive: a fuller account would no doubt cover other powers and mechanisms, and also examine how these causal powers combine to cause specific linguistic phenomena.

Not all realists will agree with this paper's analysis. Realism as a philosophical doctrine or a class of such doctrines does not generate one and only one possible way of thinking about language, or indeed one and only one way of thinking about any other substantive phenomenon. It is not a universal key to sound theory, nor is any particular theory correct just by virtue of being a realist theory.

What, then, is the value of realism for the study of language? Primarily, I suggest, as a kind of regulatory framework. If the basic tenets of scientific realism are sound, then it generates some partial criteria by which we may judge theories. Do they, for example, identify the entities that are exercising causal powers in a given set of cases; do they offer plausible accounts of the mechanisms that produce these powers (plausible, usually, in the sense of being consistent with other things that we believe we know); and do they show how these powers may interact with others to produce the kind of phenomena we are studying?

This is not a framework that exempts us from conventional ways of testing theories. We still need to compare their implications against our experience of the world, using whatever methods offer the most rigorous tests. But it is a framework we can use to help generate useful hypotheses by thinking through the ontology of the forces we seem to be dealing with. This is what I have done, for example, in developing the concept of norm circles, and what Archer has done in developing the concept of the Cultural System. 


\section{References}

ARCHER, M.S. (1995). Realist Social Theory: The Morphogenetic Approach. Cambridge: Cambridge UP.

ARCHER, M.S. (1996 [1988]). Culture and Agency. Cambridge: Cambridge UP.

ARCHER, M.S., \& ELDER-VASS, D. (2012). Cultural System or Norm Circles? An Exchange. European journal of social theory, 15, 93-115.

BEAUGRANDE, R.D. (1998). Performative speech acts in linguistic theory: The rationality of Noam Chomsky. Journal of Pragmatics, 29, 765-803.

BHASKAR, R. (1975). A realist theory of science. Leeds: Leeds Books.

BHASKAR, R. (1993). Dialectic: the pulse of freedom. London: Verso.

BHASKAR, R. (1998 [1979]). The possibility of naturalism. London: Routledge.

BLOOR, D. (1974). Popper's mystification of objective knowledge. Science Studies, 4, 65-76.

BUNGE, M. (2003). Emergence and convergence. Toronto: University of Toronto Press.

BURR, V. (2003). Social Constructionism. Hove: Routledge.

CARTER, B., \& SEALEY, A. (2000). Language, structure and agency: What can realist social theory offer to sociolinguistics? Journal of Sociolinguistics, 4, 320.

CHOMSKY, N. (1993). Language and Thought. London: Moyer Bell.

CHOMSKY, N. (2000). New Horizons in the Study of Language and Mind. Cambridge: Cambridge UP.

COLLIER, A. (1998). Language, Practice and Realism. In I. Parker (Ed.), Social Constructionism, Discourse and Realism (pp. 47-58). London: Sage.

COLLINS, J. (2008). Chomsky: A guide for the perplexed. London: Continuum.

DEVITT, M., \& STERELNY, K. (1999). Language and Reality. Cambridge MA: MIT Press.

EDWARDS, D., ASHMORE, M., \& POTTER, J. (1995). Death and Furniture. History of the Human Sciences, 8, 25-49.

ELDER-VASS, D. (2010a). The Causal Power of Social Structures. Cambridge: Cambridge UP.

ELDER-VASS, D. (2010b). The Emergence of Culture. In G. Albert \& S. Sigmund (Eds.), Soziologische Theorie kontrovers. Wiesbaden: VS Verlag.

ELDER-VASS, D. (2011). The causal power of discourse. Journal for the Theory of Social Behaviour, 41, 143-160.

ELDER-VASS, D. (2012). The Reality of Social Construction. Cambridge: Cambridge UP.

ELMAN, J.L. (1999). The Emergenc of Language: A Conspiracy Theory. In B. MacWhinney (Ed.), The Emergence of Language (pp. 1-25). Mahwah, NJ: Lawrence Erlbaum.

GERGEN, K.J. (1999). An invitation to social construction. London: Sage.

GROFF, R. (2008). Revitalizing causality, Routledge studies in critical realism ; 18 (pp. xiv, 265 p.). London: Routledge.

HALLIDAY, M.A.K. (1978). Language as Social Semiotic. London: Edward Arnold.

HALLIDAY, M.A.K. (1991). Corpus studies and probabilistic grammar. In K. Ajmer \& B. Altenberg (Eds.), English Corpus Linguistics. London: Longman.

HALLIDAY, M.A.K. (2007). Language and Society. London: Continuum.

D. Elder-Vass 
HARRIS, R. (2003). Saussure and his interpreters. Edinburgh: Edinburgh UP.

HORNSTEIN, N. (2005). Empiricism and rationalism as research strategies. In J.

McGilvray (Ed.), The Cambridge Companion to Chomsky (pp. 145-163).

Cambridge: Cambridge UP.

HUDSON, R.A. (1980). Sociolinguistics. Cambridge: Cambridge University Press.

HYMES, D. (1972). On Communicative Competence. In J. B. Pride \& J. Holmes

(Eds.), Sociolinguistics: Selected Readings (pp. 269-293). Harmondsworth: Penguin.

JONES, P.E. (2003). Critical realism and scientific method in Chomsky's linguistics. In J. Cruickshank (Ed.), Critical Realism: The difference it makes (pp. 90107). Abingdon: Routledge.

JOSEPH, J.E. (2004). The linguistic sign. In C. Sanders (Ed.), The Cambridge Companion to Saussure (pp. 59-75). Cambridge: Cambridge UP.

LAWSON, T. (1997). Economics and reality. London: Routledge.

NELLHAUS, T. (1998). Signs, Social Ontology, and Critical Realism. Journal for the Theory of Social Behaviour, 28, 1-24.

OGDEN, C.K., \& RICHARDS, I.A. (1923). The meaning of meaning. London: Kegan Paul, Trench, Trubner.

PATEMAN, T. (1987). Language in mind and language in society : studies in linguistic reproduction. Oxford: Clarendon.

PETTITO, L.-A. (2005). How the brain begets language. In J. McGilvray (Ed.), The Cambridge Companion to Chomsky (pp. 84-101). Cambridge: Cambridge UP.

POPPER, K.R. (1979). Objective knowledge. Oxford: Clarendon Press.

SAUSSURE, F.D. (1986 [1916]). Course in General Linguistics. Chicago: Open Court.

SEALEY, A. (2009). Probabilities and Surprises: A Realist Approach to Identifying Linguistic and Social Patterns, with Reference to an Oral History Corpus. Applied Linguistics, 31/2, 215-235.

SEALEY, A., \& CARTER, B. (2004). Applied linguistics as social science. London: Continuum.

SEARLE, J.R. (2002). End of the Revolution. New York Review of Books, Feb 28, 33 36.

SINCLAIR, J. (1991). Corpus, Concordance, Collocation. Oxford: Oxford UP.

SMITH, C. (2010). What is a person? Chicago: University of Chicago Press.

VOLOSINOV, V.N. (1996). Toward a Marxist philosophy of language. In P. Cobley (Ed.), The Communication Theory Reader (pp. 70-87). Abingdon: Routledge.

WOLFRAM, W. (2003). On the Construction of Vernacular Dialect Norms. In C. B. Paulston \& G. R. Tucker (Eds.), Sociolinguistics: the essential readings. Malden, MA: Blackwell. 